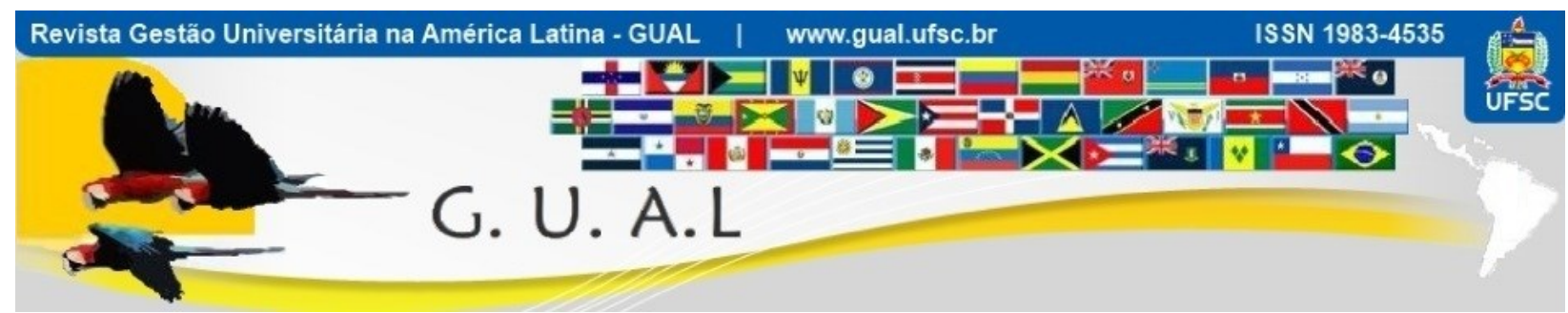

DOI: http://dx.doi.org/10.5007/1983-4535.2018v11n4p100

\title{
SISTEMAS LEVEMENTE ARTICULADOS E LÓGICA DA CONFIANÇA: O CONTROLE DOS COORDENADORES SOBRE A ATIVIDADE DOCENTE NA EAD ONLINE
}

\author{
LOOSELY COUPLED SYSTEMS AND LOGIC OF CONFIDENCE: THE \\ CONTROL OF COORDINATORS ON TEACHING ACTIVITY IN ONLINE \\ DISTANCE EDUCATION
}

Henrique Sérgio Barros Cavalcanti Júnior, Mestre Tribunal de Contas da União - TCU

h_sbcj@yahoo.com.br

José Ricardo Costa de Mendonça, Doutor Universidade Federal de Pernambuco - UFPE jrcm@ufpe.br

Fernanda Roda de Souza Araújo Cassundé, Doutora Universidade Federal do Vale do São Francisco - UNIVASF fernanda.roda@univasf.edu.br

Recebido em 24/novembro/2017

Aprovado em 06/setembro/2018

Sistema de Avaliação: Double Blind Review

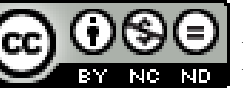

Esta obra está sob uma Licença Creative Commons Atribuição-Uso. 


\title{
RESUMO
}

A EAD online é um fenômeno cada vez mais presente no âmbito universitário. A inserção desta modalidade de ensino tem o potencial de modificar as relações tradicionais nas universidades, pois traz novos atores, ferramentas de interação e relações de trabalho. Entre as temáticas relacionadas à educação a distância online, o processo de controle começa a ganhar relevância, mas ainda carece de maiores investigações. Dessa forma, foi realizado um estudo qualitativo básico em um bacharelado em administração, de uma IES pública, com o objetivo de investigar como se dá o controle dos coordenadores sobre a atividade docente, a partir dos conceitos de sistemas levemente articulados e lógica da confiança, ambos ligados à teoria institucional. A pesquisa utilizou as seguintes técnicas de coleta de dados: entrevistas semiestruturadas, notas de campo, observação não participante do ambiente virtual de aprendizagem e análise documental. Os resultados indicam que a coordenação pode utilizar variados mecanismos de controle para monitorar as atividades docentes. Todavia, esses mecanismos geralmente são debilitados. Em parte, por causa disso, o conceito de sistemas levemente articulados mostra-se condizente com o contexto investigado. Já o conceito de lógica da confiança mostra-se mais fragilizado em suas dimensões.

Palavras-chave: EAD Online. Atividade Docente. Controle. Sistemas Levemente Articulados. Lógica da Confiança.

\begin{abstract}
Online distance education is a phenomenon that is increasingly in universities. The insertion of this modality of teaching has the potential to modify the traditional relations in the universities, because it brings new actors, tools of interaction and labor relations. Among the topics related to online distance education, the process of control begins to gain relevance, but still needs further investigation. Thus, a basic qualitative study was conducted in a bachelor's degree in administration from a public institution, with the objective of investigating how the coordinators control the teaching activity, from the concepts of loosely coupled systems and logic of trust, both linked to institutional theory. The research used the following techniques of data collection: semi-structured interviews, field notes, non-participant observation of the virtual learning environment and documentary analysis. The results indicate that coordination may use a variety of control mechanisms to monitor teaching activities. However, these mechanisms are generally weakened. In part, because of this, the concept of loosely coupled systems is consistent with the context investigated. On the other hand, the concept of trust logic is more fragile in its dimensions.
\end{abstract}

Keywords: Online EAD. Teaching activity. Control. Loosely Coupled Systems. Logic of Trust. 


\section{SISTEMAS LEVEMENTE ARTICULADOS E LÓGICA DA CONFIANÇA: O CONTROLE DOS COORDENADORES SOBRE A ATIVIDADE DOCENTE NA EAD ONLINE \\ DOI: http://dx.doi.org/10.5007/1983-4535.2018v11n4p100}

\section{INTRODUÇÃO}

No Brasil há uma forte demanda educacional que não consegue ser suprida apenas pelo ensino presencial tradicional, como também existe a necessidade da adoção das novas tecnologias da informação e comunicação (TIC) nas atividades pedagógicas, no intuito de melhorar a qualidade do ensino e adequá-lo aos desafios do século XXI (BELLONI, 2009; CASSUNDÉ, MENDONÇA, BARBOSA, 2016). É diante desta conjuntura que a educação a distância (EAD) online alcança gradativamente maior relevância no ensino superior.

No âmbito universitário brasileiro, pode-se notar uma clara tendência de crescimento da EAD. Em 2000, os cursos de graduação a distância não alcançavam 0,05\% das matrículas no ensino superior, ao passo que quatorze anos depois, em 2014 , já atingiam cerca de $24 \%$ (INEP, 2016).

No caso das universidades públicas, o aumento do número de alunos em cursos em EAD online é impulsionado especialmente por meio da Universidade Aberta do Brasil (UAB). Criada pelo governo federal, a UAB faz referência a um sistema nacional voltado para a pesquisa e para a educação superior à distância online, formado por IES públicas e articulação com polos de apoio presencial mantidos por prefeituras ou secretarias de educação estaduais (ZUIN, 2006).

Devido à importância da UAB dentro deste cenário de expansão da EAD no Brasil, trabalhos têm sido desenvolvidos sobre os seus cursos de graduação e o seu próprio sistema. Dentre essas investigações, o controle exercido pelos coordenadores sobre os professores e suas atividades tem começado a se tornar um tema de discussão, com a literatura apresentando perspectivas divergentes.

Nos estudos organizacionais, por exemplo, as análises das instituições educacionais, em especial as universidades, surgem a partir dos anos 60 (HARDY; FACHIN, 1996). Desde então, grande parte das investigações inferiram que as organizações universitárias se singularizavam no que diz respeito à dinâmica dos elementos de coordenação e supervisão sobre os atores, especialmente sobre os professores. Frequentemente, faltavam a essas instituições o alto grau de centralização e controle sobre os indivíduos, características da burocracia weberiana, e preponderavam a cerimonialização das normas organizacionais e a forte autonomia dos atores.

Por causa desse controle mais brando sobre os indivíduos, juntamente com um forte aspecto cerimonial das normas organizacionais, as universidades terminaram por ser 


\section{SISTEMAS LEVEMENTE ARTICULADOS E LÓGICA DA CONFIANÇA: O CONTROLE DOS COORDENADORES SOBRE A ATIVIDADE DOCENTE NA EAD ONLINE \\ DOI: http://dx.doi.org/10.5007/1983-4535.2018v11n4p100}

apontadas como sistemas levemente articulados (SLA) (WEICK, 1976). Além desses dois aspectos, sistemas levemente articulados são caracterizados por manter problemas sem resolução por um longo tempo e poucas interações e relações de dependência entre os atores internos (WEICK, 1976). Essas são as quatro propriedades principais dos SLA.

Na perspectiva de Meyer e Rowan (1991), diante da maior autonomia dos atores, ao invés de mecanismos de controle burocráticos, o que possui maior importância na coordenação organizacional termina por ser a lógica da confiança (LC). Basicamente, essa é a postura, disseminada entre os membros da organização, de proteger a imagem aparente si e dos outros e, dessa forma, manter as categorias e legitimidade organizacional, deixando a impressão de que as coisas estão funcionando como deveriam funcionar (DANIEL; OKEAFOR, 1987). Conforme Daniel e Okeafor (1987), a lógica da confiança, em organizações educacionais, abrange quatro características principais: 0 mito do profissionalismo, a rejeição a mecanismos de supervisão, discrição e respeito, e tolerância para com os erros observados.

De forma contrária às ideias apresentadas pelos conceitos de sistemas levemente articulados e de lógica da confiança, determinados trabalhos têm enfatizado a prática docente como fortemente delimitada no âmbito da UAB (LAPA; PRETTO, 2010; DEL PINO; GRUTZMANN; PALAU, 2011). No entanto, ao mesmo tempo, outros trabalhos têm apontado na direção contrária, defendendo que os mecanismos de supervisão sobre a atividade docente raramente funcionam dentro dos cursos, mesmo nos ambientes virtuais de aprendizagem (AVA), e os coordenadores possuem pouco controle sobre os professores e as suas atividades (BATTISTELLA; ARENHARDT; GROHMANN, 2012; KICH et al., 2012).

Assim, tendo em vista os motivos e conceitos explicitados anteriormente, o questionamento que norteia este artigo pode ser apresentado de acordo com a seguinte pergunta de pesquisa: como se dá o controle dos coordenadores sobre a atividade docente, à luz dos conceitos de sistemas levemente articulados e de lógica da confiança, em um curso de graduação a distância em administração pertencente ao Sistema Universidade Aberta do Brasil?

\section{O CONTROLE SOBRE A ATIVIDADE DOCENTE NAS UNIVERSIDADES}

O conceito de autoridade tende a ser um termo mais enfraquecido dentro das organizações universitárias, já que os departamentos, e os próprios docentes, gozam de uma 


\section{SISTEMAS LEVEMENTE ARTICULADOS E LÓGICA DA CONFIANÇA: O CONTROLE DOS COORDENADORES SOBRE A ATIVIDADE DOCENTE NA EAD ONLINE \\ DOI: http://dx.doi.org/10.5007/1983-4535.2018v11n4p100}

autonomia ligada aos princípios tradicionais da própria instituição (REPONEN, 1999). O autor aponta que as universidades são permeadas de especialistas, professores e pesquisadores que são frequentemente avessos a regras que possam restringir a sua liberdade individual, ou mesmo rotinas e procedimentos burocráticos que possam padronizar as suas atividades. Com visão semelhante, Reis (2009) coloca que na tradição acadêmica, presente nas universidades públicas brasileiras, o docente reivindica para si um alto grau de autonomia, o qual constantemente vai de encontro a regras estabelecidas pela instituição.

$\mathrm{Na}$ perspectiva de Meyer (1975), as organizações educacionais sofrem de maior dificuldade na coordenação interna em comparação a outras organizações. Isso ocorre, especialmente, com relação ao ensino, que se constitui em uma das suas atividades centrais. Dentro dessa perspectiva, Cavedon e Fachin (2002) defendem a inexistência de supervisão sobre a atividade docente no ensino superior público. Para os autores, mecanismos que mantenham os professores dentro das regras mínimas impostas pela instituição são difíceis de ser operacionalizados em face da dispersão dos locais onde as aulas são ministradas. Além disso, nos casos que exigem a necessidade de uma atitude punitiva por parte da organização, esbarra-se em procedimentos que demandam tempo e que, por vezes, se mostram inócuos diante da situação.

Dentro desse contexto, de forte autonomia dos atores e amenização por parte dos mecanismos de supervisão, os conceitos de sistemas levemente articulados e de lógica da confiança ganham relevância. Ambos se inserem dentro de uma perspectiva que aponta para um controle de caráter mais cerimonial do que burocrático dentro das organizações universitárias.

Conformar-se com as diretrizes institucionalizadas pelo Estado, que vão contra as práticas autônomas tradicionais das universidades, pode, muitas vezes, ser deveras conflituoso para os membros da organização. Em situações semelhantes, como apontado por Meyer e Rowan (1991), o que acontece é que se deixa a organização levemente articulada, com as práticas destoando em alto grau das normas e valores formalmente expostos. Todavia, como esse fenômeno traz consigo o risco de acentuação da desordem interna, surge a lógica da confiança para manter a organização funcionando, pelo menos na aparência, de forma correta (AURINI, 2006; KONDAKCI; VAN DEN BROECK, 2009). Ambos os conceitos serão apresentados nas seções seguintes. 


\section{SISTEMAS LEVEMENTE ARTICULADOS E LÓGICA DA CONFIANÇA: O CONTROLE DOS COORDENADORES SOBRE A ATIVIDADE DOCENTE NA EAD ONLINE \\ DOI: http://dx.doi.org/10.5007/1983-4535.2018v11n4p100}

\section{SISTEMAS LEVEMENTE ARTICULADOS}

As perspectivas organizacionais inspiradas no conceito de burocracia trouxeram os pressupostos de que, por meio de alterações racionais na coordenação, no planejamento e nas regras, tanto os problemas internos às instituições educacionais poderiam ser reparados, como essas também poderiam ser conduzidas a um maior nível de produtividade (MARSHALL, 1985).

Todavia, importa dizer que ao se apontar organizações educacionais como portando características de sistemas levemente articulados, não se quer dizer que dentro da universidade não existam elementos de cunho burocrático ou mesmo fortemente articulados. Como argumenta Lutz (1982), as instituições universitárias são burocracias em muitos aspectos, pois requerem que uma série de procedimentos seja seguida para o seu funcionamento. Assim, uma das primeiras características das organizações como SLA é que os atores e departamentos dentro destas, embora estejam relacionados entre si, também preservam concomitantemente um alto grau de independência. Nessa perspectiva, as interações entre os atores e entre os setores internos da instituição tendem a ser, por vezes, infrequentes, fracas e, até mesmo, de pouca importância (ORTON; WEICK, 1990).

Weick $(1976,1982)$ esclarece que esse maior isolamento dos atores termina, então, por fazer com que possíveis problemas ou irregularidades, em determinado departamento, afetem pouco os outros departamentos. Dessa forma, problemas permanecem relativamente isolados sem influenciar o funcionamento do resto da organização. No entanto, da mesma forma, esse isolamento faz com que soluções para reparar distúrbios tenham dificuldades em ser executadas com celeridade, ou mesmo levadas adiante. Assim, problemas também são mantidos sem solução por um longo período (WEICK, 1976).

Outra característica interna dos SLA é a existência debilitada de mecanismos de controle sobre os atores, de modo que aqueles existem frequentemente apenas para constar e possuem um aspecto deveras cerimonial (WEICK, 1976, 1982). Diante de uma supervisão mais branda sobre os atores, Weick (1982) lembra o fato de que antes mesmo de soluções de problemas poderem ser executadas, a aferição de erros já é difícil de acontecer. Apesar disso, as organizações levemente articuladas preservam e executam mecanismos de controle. Porém, o que acontece é que esses ficam, na maioria das vezes, restritos a agir sobre classificações formais. Em outras palavras, pode-se colocar que os documentos e as regras são estritamente supervisionados (WEICK, 1976, 1982; MEYER; ROWAN, 1978). O objetivo principal disso 


\section{SISTEMAS LEVEMENTE ARTICULADOS E LÓGICA DA CONFIANÇA: O CONTROLE DOS COORDENADORES SOBRE A ATIVIDADE DOCENTE NA EAD ONLINE \\ DOI: http://dx.doi.org/10.5007/1983-4535.2018v11n4p100}

é preservar as categorias legitimadas dentro e fora da instituição, fazendo com que a organização mantenha reconhecimento e aceitação externa (MEYER; ROWAN, 1978; 1991).

$\mathrm{Na}$ seção seguinte, será apresentado mais detalhadamente o conceito de lógica confiança, o qual é fortemente associado ao de sistemas levemente articulados.

\section{LÓGICA DA CONFIANÇA}

No trabalho intitulado Institutionalized organizations: formal structure as myth and ceremony, um dos principais artigos que estão inseridos dentro da corrente do neoinstitucionalismo organizacional, Meyer e Rowan (1991) apontam que o que impera em várias organizações, no lugar de controles efetivos, é a lógica da confiança (LC).

Segundo Meyer e Rowan (1978), a LC é basicamente o processo de preservação da imagem de si e dos outros para, dessa forma, manter a legitimidade da organização, deixando a impressão de que as coisas estão funcionando como deveriam funcionar. Para Meyer e Rowan (1991), a lógica da confiança envolve uma postura de boa fé, por parte dos membros de dentro da organização, ou mesmo de fora dessa, de que os seus colegas irão executar suas tarefas e atividades de uma maneira aceitável, sem necessitar de uma forte supervisão.

Uma das mais visíveis manifestações da lógica da confiança é o mito do profissionalismo (MEYER; ROWAN, 1991, 1978). Esse mito aponta que os professores são profissionais que se singularizam por ser altamente treinados e instruídos, o que faz com que não necessitem sofrer, ou não devam sofrer, interferências por parte dos gestores na execução de suas atividades, especialmente nas práticas de ensino. Por conta disso, à medida que os professores vão adquirindo maior experiência e titulação, ao longo da carreira, passam a receber maior confiança por parte dos seus colegas e da coordenação (DANIEL; OKEAFOR, 1987).

Além disso, os professores e outros atores, dentro das organizações educacionais, coadunam de uma forte rejeição para com mecanismos de supervisão, principalmente sobre a atividade docente. Esse fenômeno é a segunda característica da lógica da confiança. Uma postura em prol da não existência de mecanismos de supervisão, ou, pelo menos, de mecanismos de supervisão que não sejam constantes. Meyer e Rowan (1991) justificam essa postura, por parte dos atores, afirmando que ferramentas dessa natureza, quando em funcionamento, violam explicitamente o pressuposto de que todo mundo está agindo com competência, levando à diminuição da confiança e estabilidade interna, visto que aspectos 


\section{SISTEMAS LEVEMENTE ARTICULADOS E LÓGICA DA CONFIANÇA: O CONTROLE DOS COORDENADORES SOBRE A ATIVIDADE DOCENTE NA EAD ONLINE \\ DOI: http://dx.doi.org/10.5007/1983-4535.2018v11n4p100}

cerimoniais das organizações ficam ameaçados.

O terceiro atributo da LC é o respeito pelos professores, de modo que possíveis confrontações, quando tenham a possibilidade de realmente vir a acontecer, sejam minimizadas (DANIEL; OKEAFOR, 1987). Pode-se exemplificar esse fenômeno por meio de duas situações: quando os coordenadores alertam previamente aos professores sobre uma possível visita à classe; ou quando os coordenadores mostram apoio aos professores frente a alguma reclamação sobre a atividade docente, mesmo antes de poderem apurar de forma adequada a situação (OKEAFOR; LICATA; ECKER, 1987).

Por fim, a quarta e última característica do conceito é a tolerância, por parte dos coordenadores e professores, para com erros desses últimos na prática docente, quando fique claro que eles realmente aconteceram. Com a fraca supervisão das atividades docentes, ineficiências e inadequações nas práticas de ensino já tenderiam por si só a serem ocultadas (DANIEL; OKEAFOR, 1987; OKEAFOR; LICATA; ECKER, 1987), somado a isso, os professores e os administradores tendem a minimizar ou "fazer vista grossa" aos possíveis erros ou más condutas aferidas. Dessa forma, os coordenadores desconsideram a regra e fingem não perceber o não cumprimento dela por parte dos professores, desde que estes tenham um compromisso mínimo com os resultados e a produtividade (MEYER; ROWAN, 1991).

Diante do que propõe este trabalho em seus objetivos, faz-se necessário maior atrelamento dos conceitos previamente apresentados com a EAD online e seus aspectos, o que está sendo discutido na seção a seguir.

\section{O CONTROLE NA EDUCAÇÃO A DISTÂNCIA ONLINE}

Ao analisar a organização de vários tipos de ambientes virtuais de aprendizagem (AVA), Lima e Loureiro (2012) defendem que a maior parte desses é caracterizada pela manutenção de relações controladoras e disciplinadoras. Segundo os autores, as ferramentas que os sistemas disponibilizam não garantem nenhum tipo de ação mais aberta por parte dos docentes, já que são percebidos na maioria dos AVA mecanismos como controle de acesso, administração absoluta de todos os espaços, controle de tempo, monitoramento dos contatos entre grupos, espaços delimitados, etc. Muitos destes controles são justificados em razão da necessidade organizacional, do controle de fraudes e de outras ações que visam o "bem-estar da comunidade" institucional. Entretanto, Dias Junior e Ferreira (2007) defendem que a 


\section{SISTEMAS LEVEMENTE ARTICULADOS E LÓGICA DA CONFIANÇA: O CONTROLE DOS COORDENADORES SOBRE A ATIVIDADE DOCENTE NA EAD ONLINE \\ DOI: http://dx.doi.org/10.5007/1983-4535.2018v11n4p100}

avaliação docente no AVA precisa ser mais bem apoiada, de forma a incorporar uma análise de dados de caráter mais qualitativo. Nisso, o nível de detalhe das funcionalidades das ferramentas disponíveis no AVA pode contemplar tanto os comentários, quanto uma análise mais refinada das próprias interações docente-discente no ambiente virtual.

Importa dizer que o controle dos atores e suas atividades é um aspecto importante da gestão de cursos de EAD online (MOORE; KEARSLEY, 2011; ALMEIDA; PIMENTEL; STIUBIENER, 2012), não sendo restrito só ao AVA. Botelho e Maffra (2009) argumentam que o monitoramento das mediações interativas é um processo relevante dentro da EAD. Por isso, faz-se necessária uma avaliação do que se está fazendo nas interações de ensino, bem como refletir e averiguar se os profissionais que estão utilizando os recursos tecnológicos estão preparados para fazê-lo, uma vez que a EAD exige da parte dos professores e tutores uma formação continuada e permanente.

Considerando a discussão teórica até aqui apresentada, pode-se começar a vislumbrar o fato de que embora possa haver controle sobre regras e padrões, é possível que exista pouca supervisão por parte da coordenação para checar se eles são realmente seguidos. Junto com a amenização dos mecanismos de controle, a pouca interação e independência dos atores entre si, além da manutenção de problemas em longo prazo, são características presentes em sistemas levemente articulados, principalmente no âmbito universitário.

Somado a isso, é importante colocar que em organizações educacionais públicas, onde o Estado é o principal regulador e o controle do mercado é mais brando, como é o caso dos cursos de EAD em IPES, aspectos institucionais e cerimoniais da organização são mais propícios a ganhar preponderância frente aos aspectos técnicos (AURINI, 2006). Nesse contexto, para proteger a imagem aparente de si e dos outros e, dessa forma, manter as categorias e legitimidade organizacional, deixando a impressão de que as coisas estão funcionando como deveriam funciona, surge a lógica da confiança.

\section{METODOLOGIA}

Antes de apresentar os procedimentos metodológicos importa definir a visão de mundo dos pesquisadores, pois são os pressupostos adotados no nível paradigmático que determinam a coerência entre a noção de sujeito e as relações com o objeto de investigação, e acabam por definir a escolha metodológica de investigação (MORGAN; SMIRCICH, 1980).

Neste trabalho, foi adotado o paradigma interpretativista. Conforme Lincoln e Guba 


\section{SISTEMAS LEVEMENTE ARTICULADOS E LÓGICA DA CONFIANÇA: O CONTROLE DOS COORDENADORES SOBRE A ATIVIDADE DOCENTE NA EAD ONLINE \\ DOI: http://dx.doi.org/10.5007/1983-4535.2018v11n4p100}

(2006), esse paradigma parte do princípio de que existe toda uma riqueza na construção de conceitos e instituições no âmbito da sociedade, que, na maioria das vezes, não pode ser aferida objetivamente. Nesse sentido, a abordagem metodológica adotada foi a qualitativa, pois na perspectiva de Denzin e Lincoln (2006), esta ressalta uma ênfase sobre as qualidades das entidades e sobre os processos e os significados, frisando uma realidade socialmente construída, aproximando-se, assim, dos pressupostos interpretativos. A estratégia de pesquisa definida, portanto, foi a do estudo qualitativo interpretativo básico, o qual tem sido apontado por vários autores como uma relevante estratégia de pesquisa (CAELLI et al., 2003; MARIZ et al., 2005). Para Merriam (1998), essa estratégia tem o objetivo de descrever e entender um fenômeno, processo ou perspectiva de mundo das pessoas envolvidas; e tipicamente utiliza teoria, modelos e conceitos a priori.

O lócus de pesquisa foi um bacharelado a distância em administração, integrado ao Sistema Universidade Aberta do Brasil. Deve-se acrescentar ainda que, ao escolher este locus, os pesquisadores tiveram a acessibilidade necessária para com os sujeitos de pesquisa e documentos, que proporcionaram a obtenção dos dados para concretização deste trabalho.

Desde que a generalização não é o principal objetivo da pesquisa qualitativa, a seleção intencional foi adotada neste estudo. Assim, escolhem-se sujeitos com os quais se esperava encontrar grande quantidade de informação para responder às questões de pesquisa (MERRIAM, 1998; MORROW, 2005). Estes sujeitos foram: o professor-titular, que perde parte da autonomia que tinha na condução do ensino, quando este era somente presencial, mas não deixa de forma alguma de ser um ator relevante; o professor-tutor, um personagem relativamente novo, também considerado docente, que surge com grande importância devido a forte proximidade que deve ter com o discente; e o coordenador, o qual possui o difícil papel de organizar e monitorar uma diversidade de colaboradores, com habilidades distintas, em um ambiente educacional complexo.

Como estratégia de coleta de dados foram utilizadas a entrevista semiestruturada, observação não participante, estruturada, por meio de um roteiro pré-determinado, a análise documental e as notas de campo. Estas últimas serviram para documentar observações feitas durante a aplicação das entrevistas, sendo redigidas logo após a finalização dessas. A análise documental, neste trabalho, debruçou-se sobre o plano pedagógico do curso (PPC) e documentos presentes nas páginas na web da IPES, do Ministério da Educação e da própria UAB. Dessa forma, analisaram-se especialmente documentos de caráter público. Já as 


\section{SISTEMAS LEVEMENTE ARTICULADOS E LÓGICA DA CONFIANÇA: O CONTROLE DOS COORDENADORES SOBRE A ATIVIDADE DOCENTE NA EAD ONLINE \\ DOI: http://dx.doi.org/10.5007/1983-4535.2018v11n4p100}

entrevistas foram realizadas com 12 sujeitos e tiveram uma média de 54 minutos de duração.

Neste trabalho, empregou-se a análise categorial, que é uma das técnicas da análise de conteúdo (AC) (BARDIN, 2011). As categorias, as dimensões e os indicadores foram definidos a priori, com base no referencial teórico, e estão apresentadas no quadro 1 abaixo.

Quadro 1 Controle: dimensões e indicadores

\begin{tabular}{|c|c|c|c|}
\hline Categoria & Dimensão & Indicadores & Fontes \\
\hline \multirow{5}{*}{ Controle } & Direto & $\begin{array}{l}\text { - vigilância expressa e constante por atores ou } \\
\text { ferramentas tecnológicas; } \\
\text { - uma pessoa é responsável pela(s) outra(s). }\end{array}$ & \multirow{5}{*}{$\begin{array}{l}\text { Baseado } \\
\text { em Ouchi } \\
\text { (1979); } \\
\text { Pérez } \\
\text { Vilariño e } \\
\text { Schoenher } \\
\text { r (1987); e } \\
\text { Mintzberg } \\
\text { (2011) }\end{array}$} \\
\hline & Mercadológico & $\begin{array}{l}\text { - capacidade de aferição dos resultados do } \\
\text { trabalho; - necessidade de certa simplificação da } \\
\text { natureza trabalho. }\end{array}$ & \\
\hline & Burocrático & 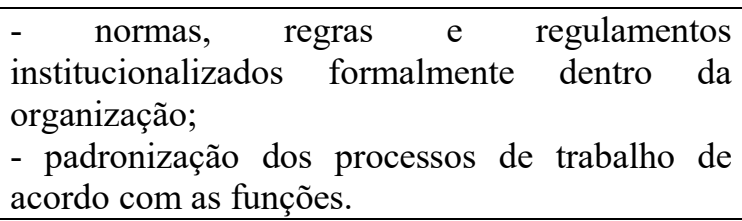 & \\
\hline & Cultural & $\begin{array}{l}\text { - crenças e valores amplamente compartilhadas } \\
\text { entre os atores; - padronização das qualificações. }\end{array}$ & \\
\hline & Ad hoc & $\begin{array}{l}\text { - comunicação informal entre atores como forma } \\
\text { de ajustes dos processos organizacionais; } \\
\text { - divisão das tarefas não está claramente definido } \\
\text { na organização. }\end{array}$ & \\
\hline \multirow{4}{*}{$\begin{array}{l}\text { Sistemas } \\
\text { levemente } \\
\text { articulados }\end{array}$} & $\begin{array}{l}\text { Baixa interação } \\
\text { dependência entre } \\
\text { atores }\end{array}$ & $\begin{array}{l}\text { - Interações inconstantes e fracas entre atores; } \\
\text { - Forte autonomia dos atores. }\end{array}$ & \multirow{4}{*}{$\begin{array}{l}\text { Baseado } \\
\text { em Weick } \\
(1976, \\
1982) \\
\text { Orton e } \\
\text { Weick } \\
(1990)\end{array}$} \\
\hline & $\begin{array}{l}\text { Problemas mantidos } \\
\text { sem resolução }\end{array}$ & $\begin{array}{l}\text { s permanecem isolados; } \\
\text { des para reparar distúrbios. }\end{array}$ & \\
\hline & $\begin{array}{lr}\text { Baixa utilização } & \mathrm{e} \\
\text { ineficiência } & \text { de } \\
\text { mecanismos } & \text { de } \\
\text { controle } & \end{array}$ & $\begin{array}{l}\text { - Mecanismos de controle debilitados } \\
\text { - Dificuldades em aferir problemas }\end{array}$ & \\
\hline & $\begin{array}{l}\text { Controle cerimonial } \\
\text { sobre normas }\end{array}$ & $\begin{array}{l}\text { - Forte controle sobre regras formais } \\
\text { - Categorias racionalizadas contraditórias entre si }\end{array}$ & \\
\hline \multirow{4}{*}{$\begin{array}{l}\text { Lógica da } \\
\text { confiança }\end{array}$} & $\begin{array}{l}\text { Mito } \\
\text { profissionalismo }\end{array}$ & $\begin{array}{l}\text { - Professores não devem sofrer interferências nas } \\
\text { práticas de ensino } \\
\text { - Quanto maior a experiência/titulação, maior a } \\
\text { confiança recebida }\end{array}$ & \multirow{4}{*}{$\begin{array}{l}\text { Baseado } \\
\text { em Daniel } \\
\text { e Okeafor } \\
(1987) \text {, } \\
\text { Okeafor et } \\
\text { al. (1987) } \\
\text { e Meyer e } \\
\text { Rowan } \\
(1991)\end{array}$} \\
\hline & $\begin{array}{l}\text { Rejeição a mecanismos } \\
\text { de supervisão }\end{array}$ & $\begin{array}{l}\text { - Rejeição a mecanismos de monitoramento } \\
\text { sobre os professores }\end{array}$ & \\
\hline & Discrição e respeito & $\begin{array}{l}\text { - Coordenadores mostram apoio aos professores } \\
\text { frente a reclamações para com eles } \\
\text { - Coordenadores alertam previamente os } \\
\text { professores sobre supervisões }\end{array}$ & \\
\hline & $\begin{array}{l}\text { Tolerância para com } \\
\text { erros observados }\end{array}$ & $\begin{array}{l}\text { - Tendência de minimizar os erros dos } \\
\text { professores } \\
\text { - Fingir não perceber problemas na conduta dos } \\
\text { professores }\end{array}$ & \\
\hline
\end{tabular}

Fonte: elaboração dos autores (2017) 


\section{SISTEMAS LEVEMENTE ARTICULADOS E LÓGICA DA CONFIANÇA: O CONTROLE DOS COORDENADORES SOBRE A ATIVIDADE DOCENTE NA EAD ONLINE \\ DOI: http://dx.doi.org/10.5007/1983-4535.2018v11n4p100}

$\mathrm{Na}$ análise das entrevistas e notas de campo, os sujeitos de pesquisa foram codificados da seguinte forma: "P1" é professor entrevistado 1, "P2" para professor entrevistado 2, e assim sucessivamente. "CC" é o coordenador do curso e "CT" é o coordenador de tutoria.

\section{RESULTADOS}

\subsection{ASPECTOS DOS MECANISMOS DE CONTROLE DOS COORDENADORES}

Ao analisar o projeto pedagógico do curso, à procura de possíveis menções sobre o processo de controle sobre os membros do bacharelado, ou mesmo alguma menção a mecanismos de avaliação de desempenho, verifica-se somente em uma parte do documento a explicitação de mecanismos de controle que podem ser utilizados para avaliar a atividade docente. Por meio da técnica da observação, no entanto, foi possível obter dados sobre os mecanismos de controle presentes no Moodle, os quais podem ser utilizados pela coordenação para monitorar o desempenho dos docentes nas atividades online. A observação estruturada foi aplicada no AVA do projeto Pró-ADM, ao qual os pesquisadores tiveram acesso.

Conforme explicam Lima e Loureiro (2012), o Moodle administra as ações dos atores por meio de mecanismos como controle de acesso, administração absoluta de todos os espaços, controle de tempo, monitoramento dos contatos entre grupos. Contudo, ao contrário do que colocam esses autores, pode-se também verificar que essas ferramentas não são absolutas. O que acontece é que esses mecanismos são basicamente quantitativos, eles dizem a quantidade de tempo que a pessoa passou conectada, o que fez, ou há quanto tempo está sem entrar. Esses dados, no entanto, não explicitam necessariamente se o professor está executando as suas atividades de forma adequada. Sendo assim, torna-se necessário que funcionários de apoio à coordenação, ou mesmo a própria coordenação, entrem no Moodle para verificar qualitativamente as atividades docentes. Essa situação pode ser verificada em trechos da entrevista com o coordenador do curso:

O acompanhamento virtual na verdade a gente já tem um funcionário [...] Que é o vicecoordenador de tutoria, que ele é responsável pra responder todos os e-mails dos alunos, pra entrar no ambiente pra ver se os professores, os tutores virtuais estão entrando, estão respondendo. Não é a assiduidade do professor no ambiente em si, mas é se aquela frequência dele no ambiente retorna de maneira satisfatória para o aluno [...] A qualidade da resposta $(\mathrm{CC})$.

Pode-se verificar, por meio do último discurso exposto, que o coordenador do curso demonstra preocupação em amenizar o aspecto quantitativo das ferramentas de 


\section{SISTEMAS LEVEMENTE ARTICULADOS E LÓGICA DA CONFIANÇA: O CONTROLE DOS COORDENADORES SOBRE A ATIVIDADE DOCENTE NA EAD ONLINE \\ DOI: http://dx.doi.org/10.5007/1983-4535.2018v11n4p100}

monitoramento no Moodle. Tal situação corrobora com as exposições feitas por Dias Júnior e Ferreira (2007), já que eles argumentam a necessidade de a avaliação docente em ambientes virtuais de aprendizagem ser mais bem apoiada, de forma a incorporar uma análise de dados de caráter qualitativo.

$\mathrm{Na}$ entrevista com o coordenador de tutoria, este identifica a presença de aspectos de controle direto na EAD, pois existem atores exercendo supervisão direta e tecnologias de monitoramento constantes sobre o docente: "Então, o pessoal do acompanhamento, principalmente, fica olhando se o tutor está entrando no ambiente, quantas horas ele passou" (CT). Segundo Mintzberg (2011), nesse tipo de controle, o direto, pessoas são responsáveis pelo trabalho de outras, fornecendo instruções e monitorando as ações dessas. Pérez Vilariño e Schoenherr (1987) acrescentaram que o controle direto pode ser percebido também pela aplicação de tecnologias que permitam o monitoramento constante dos indivíduos, como é caso do curso estudado.

Além do controle direto, pontua-se que o controle burocrático também se faz presente, segundo o próprio coordenador de tutoria: “Olhe, a gente tem um manual para os professores e um manual para os tutores. Antes de começar o curso, nós fazemos uma reunião com todos os tutores e com todos os professores. Passamos essas orientações" (CT). "Normas, regras e regulamentos institucionalizados dentro da organização" são um dos indicadores do controle burocrático que pode ser notado aqui. Além disso, ainda pode ser verificado o indicador "Padronização dos processos de trabalho de acordo com as funções", a partir de relatos de alguns docentes:

Até porque existe um descritivo de função, [...] todo mundo quando entra pra ser tutor presencial, professor virtual e executor, todos recebem um manualzinho dizendo o que cada um tem que fazer (P8).

Todavia, mesmo existindo essa padronização das funções para o professor-titular e para o professor-tutor, ela é dificilmente seguida, pois, de modo frequente, acontecem ajustes informais entre o tutor e o titular com relação às atividades que cada uma deve exercer. Aqui encontramos mais um indicador de controle ad hoc. A fala do docente P2 relata bem essa situação: 


\section{SISTEMAS LEVEMENTE ARTICULADOS E LÓGICA DA CONFIANÇA: O CONTROLE DOS COORDENADORES SOBRE A ATIVIDADE DOCENTE NA EAD ONLINE \\ DOI: http://dx.doi.org/10.5007/1983-4535.2018v11n4p100}

Por mais que se tente estabelecer uma cartilha, onde diga: a função do professor executor é essa, a função do tutor é essa, mas eu acho que acaba que no meio informal, o professor executor acaba atribuindo algumas coisas que deveria ser dele pra o tutor. Tipo: às vezes ele ta sobrecarregado de provas, e correção de prova, de acordo com o manual, deve ser feita pelo professor executor. No entanto, ele acaba transferindo para o seu tutor, que às vezes o volume é muito grande. Então, nesse ponto é que eu percebo que às vezes não ta tão delimitado... (P2).

Ao longo das entrevistas, professores apontaram constantemente que o feedback dos alunos funciona como uma espécie de mecanismo de controle, já que é comum as reclamações destes perante a coordenação quando há problemas com relação aos professores, tanto tutores como titulares. Este fato foi confirmado durante as entrevistas com a coordenação, a qual, inclusive, apresentou o interesse de ter a opinião dos alunos, sobre a qualidade dos docentes, institucionalizada como um mecanismo permanente de avaliação.

Além dos alunos, das normas explicitadas e das ferramentas disponíveis no Moodle, segundo o relato do coordenador de curso, o professor-tutor presencial do polo também presta auxílio no monitoramento da atividade docente, já que a ele cabe repassar relatórios à coordenação de curso sobre a presença dos professores-tutores e a qualidade da aula dos mesmos. Assim, verifica-se mais uma vez um dos indicadores do controle direto.

O que se pode verificar, a partir da pesquisa de campo, é a existência de tipos distintos de mecanismos de monitoramento sobre os professores dentro do curso, quais sejam: as regras repassadas pela coordenação; as ferramentas de controle presentes no Moodle; a figura do professor-tutor presencial, que age basicamente repassando informações para a coordenação; o feedback informal dos alunos, que podem reclamar perante a coordenação ou mesmo perante os professores da postura de certos docentes; e, por fim, o controle informal dos professores entre si, quando, por algum motivo, reclamam junto à coordenação de seus colegas. Portanto, podem ser apontados: o controle direto (mecanismos presentes no AVA capazes de monitorar as atividades dos docentes, além do próprio professor-tutor presencial, o qual supervisiona os professores-tutores quando esses vão dar aulas presenciais), o controle burocrático (certa padronização dos processos de trabalho, pois existem regras explícitas passadas pela coordenação do curso sobre as atividades dos docentes) e pode-se detectar o controle ad hoc (ajustes informais entre atores com relação ao processo de monitoramento dos docentes, quando chegam reclamações, por parte dos discentes e docentes, à coordenação e ajuste entre os docentes [tutor e titular] com relação às atividades que cada uma deve exercer).

Como podem ser vislumbrados modelos de controle de naturezas distintas dentro do 


\section{SISTEMAS LEVEMENTE ARTICULADOS E LÓGICA DA CONFIANÇA: O CONTROLE DOS COORDENADORES SOBRE A ATIVIDADE DOCENTE NA EAD ONLINE \\ DOI: http://dx.doi.org/10.5007/1983-4535.2018v11n4p100}

locus investigado, pode-se ver que a realidade do curso se adéqua aos estudos de Ouchi (1979) e Merchant (1982), já que defendem que nunca há só uma lógica de controle dentro da organização.

\subsection{SOBRE OS SISTEMAS LEVEMENTE ARTICULADOS NO CURSO}

A partir da década de 70, Weick (1976) começa a apontar os aspectos cerimoniais das estruturas educacionais, mostrando que mesmo as regras existindo e sendo importantes para essas organizações, as práticas diárias dos atores destoam fortemente do que está formalmente explícito. Na perspectiva do autor, o conceito de sistemas levemente articulados faz-se mais adequado para sintetizar aspectos do funcionamento das instituições educacionais.

A partir da análise das entrevistas, pode-se notar que, dentro do curso investigado, as interações mais frequentes entre atores acontecem basicamente entre o professor-titular e os professores-tutores que o auxiliam em determinada disciplina. Já as interações dos docentes com os membros da coordenação, que também são esparsas, são mais constantes em certos períodos, como ao final do semestre, em razão das pendências quando do término das disciplinas, embora tais interações raramente sejam feitas de maneira individualizada.

É pouca, a relação é bem pouca. No final do semestre, geralmente aí aumenta esse contato, porque... as pendências, né, que o pessoal tem. Geralmente eles mandam e-mail. Dificilmente você recebe ou eu recebi um e-mail individual tratando da minha disciplina. Sempre copiam todo mundo em e-mails, mesmo que não faça parte da sua disciplina (P6).

A partir dos dados apresentados, é possível verificar, que com relação à primeira dimensão de SLA (baixa interação e dependência entre os atores), seus dois principais indicadores aparecem: interações inconstantes e fracas entre atores; e forte autonomia dos atores. O primeiro indicador pode ser verificado nas relações entre a coordenação e os professores e mesmo nas relações entre os professores. Existe exceção somente no caso das interações entre o professor-titular e os professores-tutores, que estão alocados em uma mesma disciplina. Nesse caso, a interação tende a ser maior. Com relação ao segundo indicador, pode-se colocar que, a partir dos relatos dos sujeitos entrevistados, estes apontam que os professores dependem muito pouco da coordenação. A dependência entre atores, quando existe, é dos professores-tutores para com o professor-titular da disciplina ministrada.

Em grande parte, devido ao maior isolamento dos atores em SLA, possíveis problemas ou irregularidades em determinado setor afetam pouco os demais setores. Isso faz com que problemas possam permanecer isolados de modo que não venham a influenciar os 


\section{SISTEMAS LEVEMENTE ARTICULADOS E LÓGICA DA CONFIANÇA: O CONTROLE DOS COORDENADORES SOBRE A ATIVIDADE DOCENTE NA EAD ONLINE \\ DOI: http://dx.doi.org/10.5007/1983-4535.2018v11n4p100}

processos no resto da organização. No entanto, por outro lado, esse isolamento também faz com que soluções para reparar distúrbios tenham dificuldades em serem executadas com celeridade, ou mesmo serem levadas adiante. Assim, problemas também podem ficar sem solução por um longo tempo (WEICK, 1976).

Com relação à segunda dimensão do conceito de SLA (problemas mantidos sem resolução), é possível verificar que determinadas situações ficam sem solução por um longo tempo, já que a coordenação aparenta ter que lidar com problemas que se acumulam desde o começo do curso, o que acaba por afetar outros processos de sua responsabilidade, como a supervisão e o monitoramento dos docentes. Aparentemente, não há também uma estrutura qualificada no núcleo de EAD. Por fim, a questão das bolsas parece afetar o controle sobre o corpo docente, já que isso pode criar a justificativa para o não exercício correto das atividades. Contudo, verifica-se concomitantemente que os problemas não permanecem isolados sem afetar o restante da organização.

Em SLA, a existência debilitada de mecanismos de controle sobre os atores, de modo que aqueles existem frequentemente apenas para constar, é por demais presente (WEICK, 1976, 1982). Assim, a terceira dimensão de sistemas levemente articulados denomina-se: Baixa utilização e ineficiências de mecanismos de controle.

Primeiramente, nota-se pelas colocações dos entrevistados que, mesmo com mecanismos de supervisão disponíveis no AVA, os quais são capazes de registrar os acessos dos professores, esses não podem ser utilizados em toda sua capacidade. Em grande parte, isso acontece porque falta pessoal para conseguir analisar e filtrar os dados e os atores a serem supervisionados são muitos.

Tem uma pessoa só pra visualizar quantas horas a gente ta dando no ambiente. Aí tem essas reuniões pra chamar atenção, pra dizer que... o discurso é muito bonito, sabe, mas às vezes a prática não..(P1).

Por exemplo, eu fico sabendo que diariamente ou semanalmente os coordenadores, os apoios da coordenação do BAP olham se os professores entraram no ambiente, se responderam, se participaram no fórum, só que eu acho muito vago. Por exemplo, eu tenho o ambiente, entro aqui, deixo ele aberto, certo? Quem vai avaliar se eu to utilizando todos os recursos, se eu to respondendo aos alunos? Assim, então fica muito aberto esse ponto, porque você entrar... (P8).

Ao se analisar as falas dos professores, nota-se que elas vão ao encontro dos argumentos postulados por Vasconcelos e Pinochet $(2002$; 2004). Os autores colocam que frequentemente os atores organizacionais dispõem de espaços de reação, podendo furtar-se à 


\section{SISTEMAS LEVEMENTE ARTICULADOS E LÓGICA DA CONFIANÇA: O CONTROLE DOS COORDENADORES SOBRE A ATIVIDADE DOCENTE NA EAD ONLINE \\ DOI: http://dx.doi.org/10.5007/1983-4535.2018v11n4p100}

supervisão da qual são alvos. Além disso, é impossível supervisionar a todos o tempo todo. Assim, sistemas e ferramentas de gestão podem ser alvo de resistência por parte dos colaboradores da organização, existindo apenas para constar. Os discursos dos entrevistados também vão ao encontro do que é exposto pelo trabalho de Almeida, Pimentel e Stiubiener (2012), que, ao pesquisarem um curso de graduação a distância de uma IPES, colocam que, embora exista a possibilidade concreta da inserção de mecanismos de supervisão sobre a atividade docente no AVA, esses raramente são aplicados em sua plenitude. Devem ser lembradas aqui também as colocações de Ouchi (1979) com relação aos controles burocrático e suas imperfeições. Segundo o autor, todas as normas são essencialmente padrões arbitrários frente aos quais uma comparação é feita. Assim, para aplicar uma regra, um administrador deve observar o desempenho atual de algum docente, dar um valor a esse desempenho, e então comparar o valor assinalado com a regra para determinar se o desempenho foi satisfatório ou não. Tudo isso consome tempo e esforço e, caso a regra seja expressa qualitativamente, ou o trabalho não possa ser facilmente padronizado (como muitas vezes é o caso da atividade docente, inclusive na EAD), as dificuldades são ainda maiores.

No entanto, pode-se ver também, pelo discurso dos coordenadores de curso, até agora apresentados, que ao contrário do estudo de Vasconcelos e Pinochet (2002), os dirigentes não tentam passar uma imagem de que as coisas funcionam e que as tecnologias auxiliam na regulação. Eles explicitam que não têm capacidade plena de impedir que os empregados consigam se furtar ao sistema.

Os achados se assemelham aos argumentos de Eliasquevici e Prado Júnior (2008), os quais apontam as dificuldades ligadas à decisão e à execução das tarefas dos coordenadores dentro de um curso à distância por causa das complexidades advindas do alto número de colaboradores, com características distintas, envolvidos:

Mas aí a gente tá tendo, vendo se consegue pelo menos acompanhar a atuação dos professores virtualmente. Mesmo porque, mesmo que a gente não tenha condições, assim, operacionais de tá todo dia entrado no ambiente, olhando, mas pelo menos alguns dias, dois dias na semana, tal, olhando direitinho, porque no (curso) são oferecidos, nós temos três turmas, três entradas, 2010.1; 2011.1; 2011.2, são quase 400 alunos e além desses 400 alunos nós temos 10 polos [...] (CC).

Contudo, é importante pontuar que existem diferenças no controle entre docentes, de modo que os mecanismos de supervisão se mostram mais presentes sobre os professorestutores, principalmente devido ao fato de eles terem uma relação mais próxima com os 


\section{SISTEMAS LEVEMENTE ARTICULADOS E LÓGICA DA CONFIANÇA: O CONTROLE DOS COORDENADORES SOBRE A ATIVIDADE DOCENTE NA EAD ONLINE \\ DOI: http://dx.doi.org/10.5007/1983-4535.2018v11n4p100}

estudantes. Além disso, o próprio controle da atividade docente, ainda mais na EAD, é uma tarefa complexa para muitos dos entrevistados, de modo que isso contribui para que os professores acabem por ter maior autonomia.

Com relação à terceira dimensão do conceito de SLA (baixa utilização e ineficiência de mecanismos de controle), a partir da análise dos dados, é possível verificar dois indicadores: mecanismos de controle debilitados e dificuldades em aferir problemas. A adequação da supervisão branda, o outro indicador da dimensão em questão, ao locus investido é relativa, pois além dos mecanismos formais de monitoramento, há os mecanismos informais (viabilizados principalmente pelo feedback dos alunos com relação aos docentes). Além disso, existe a punição para os professores quando esses apresentam posturas errôneas:

Se ele pisar na bola e aquilo vai comprometer o trabalho da equipe [...] Não, ele é excluído, tem que ser, entendeu? Então isso aí eu não tenho a menor dificuldade de dizer por que é o que ocorre realmente, entendeu? (CC).

As organizações levemente articuladas preservam e executam mecanismos de controle. Porém, o que acontece é que esses ficam, muitas vezes, restritos a agir sobre classificações formais. Em outras palavras, pode-se colocar que os documentos e as regras são estritamente supervisionados. O objetivo principal disso é preservar as categorias legitimadas dentro e fora da instituição, fazendo com que a organização mantenha o reconhecimento e a aceitação externa (MEYER; ROWAN, 1978; 1991).

Dentro do locus investigado, essa dimensão (controle cerimonial sobre normas) pode ser aferida quando se trata de diferenciar a função de professor-executor da de professortutor. Embora a UAB, e mesmo o curso, coloquem as atividades dos professores-tutores e dos professores-titulares bem definidas, o que acontece é que a separação entre essas funções dificilmente é seguida dentro do curso:

Olhe, veja bem, eles deixam bem claro qual é o papel de tutor virtual, deixam muito claro. Só que na prática não é assim, não é assim. A gente faz muito mais do que é exigido. (P1).

Conforme Alonso (2010), é tênue a fronteira entre o trabalho do tutor e do professor. Segundo a autora, e conforme os entrevistados, é possível notar que, muitas vezes, ao tutor fica destinado à maior parte das atividades de ensino, além de já ter que executar um atendimento mais próximo aos estudantes. Um dos problemas relacionados a isso, segundo Alonso (2010), e conforme os próprios entrevistados, é que o tutor termina por não possuir, 


\section{SISTEMAS LEVEMENTE ARTICULADOS E LÓGICA DA CONFIANÇA: O CONTROLE DOS COORDENADORES SOBRE A ATIVIDADE DOCENTE NA EAD ONLINE \\ DOI: http://dx.doi.org/10.5007/1983-4535.2018v11n4p100}

profissionalmente, reconhecimento compatível com suas atribuições.

$\mathrm{Na}$ última dimensão de sistemas levemente articulados (controle cerimonial sobre normas), é possível verificar seus dois indicadores: forte controle sobre regras formais; e categorias racionalizadas contraditórias entre si. Pode-se notar o primeiro indicador no controle da coordenação sobre os currículos e na alocação de professores. Já o segundo indicador manifesta-se na separação entre as funções de titular e tutor, que, embora institucionalizada formalmente dentro do curso e reconhecida pela $\mathrm{UAB}$, é difícil de ser verificada na prática.

Assim, considerando a pesquisa de campo, compreende-se que o conceito de sistemas levemente articulados relaciona-se ao lócus investigado, pois suas quatro dimensões, embora não com todos os indicadores estipulados, encontram-se presentes.

Na próxima seção, apresentar-se-á a o resultado da análise de dados com relação à lógica de confiança entre coordenadores e professores no curso.

\subsection{A LÓGICA DA CONFIANÇA ENTRE COORDENADORES E PROFESSORES}

Ao analisar as entrevistas é possível inferir que a maioria dos entrevistados não vê relação entre titulação e autonomia a ponto de os professores serem menos monitorados pela coordenação. Para os entrevistados, a perspectiva preponderante é a que coloca que a autonomia tem ligação com a experiência dentro da EAD online, já que com ela o docente possui maior habilidade para lidar com as ferramentas e os aspectos próprios de um curso a distância. A titulação não é um fator direto de maior respeito por parte dos outros atores.

Então, assim, faz diferença, sim, a experiência, o treinamento pra autonomia em sala de aula. Titulação, sinceramente, eu acho que não. Titulação eu já vi muita gente com titulação boa, porque o professor ele não é só Academia, o professor é Academia e relacionamento interpessoal (P4).

$\mathrm{Eu}$ acho que essa coisa da titulação não faz muita diferença lá. Eu acho que a titulação só faz diferença pra te colocar no cargo (P6).

De modo geral, quando perguntados sobre seus colegas, os professores costumam responder que esses são preparados. Alguns docentes isolados alegaram que não eram, ou que antes não eram, mas agora estavam mais bem capacitados. Um aspecto que parece afetar o mito do profissionalismo, no entanto, é a natureza do vínculo profissional dos professores com o curso. Geralmente, o curso é uma opção secundária de trabalho. Assim, é possível notar que a dimensão do mito do profissionalismo aparentar ser enfraquecida dentro do curso. 


\section{SISTEMAS LEVEMENTE ARTICULADOS E LÓGICA DA CONFIANÇA: O CONTROLE DOS COORDENADORES SOBRE A ATIVIDADE DOCENTE NA EAD ONLINE \\ DOI: http://dx.doi.org/10.5007/1983-4535.2018v11n4p100}

Alguns atores defendem que existe uma relação entre a autonomia e a experiência de ensino, mas só quando essa experiência vem da vivência na própria EAD online, pois esperam que a experiência prévia na modalidade traga junto maior habilidade no uso das ferramentas do AVA.

Nesse sentido, os professores mais velhos ou os que tenham mais experiência no ensino presencial, por exemplo, não necessariamente recebem maior respeito que os outros que não têm essa experiência. Pelo contrário, muitas vezes, é possível que esses tenham até mesmo maior dificuldade de manejar as ferramentas da EAD online e demandem maior acompanhamento por parte de outros professores e da própria coordenação.

A LC e sua dimensão do mito do profissionalismo foram verificadas em ambientes onde os atores possuem considerável estabilidade e tempo de permanência, assim, a alta rotatividade dos professores, dentro do curso, pode ser um dos fatores que causa maior enfraquecimento do conceito dentro locus pesquisado. O mito do profissionalismo também pode ser afetado pelo fato de grande parte dos docentes ser ligada prioritariamente a IES privadas, onde se pode ter menos pesquisa e menos importância para com a titulação do profissional.

Importa salientar, no entanto, que mesmo dentro desse contexto, as IPES, por meio de seu núcleo de EAD e o próprio coordenador de curso, o qual é concursado da instituição, participando inclusive de programa de pós-graduação strictu sensu, dão maior importância à titulação, pois restringem certas disciplinas a professores da casa e associam qualidade a títulos acadêmicos. Dessa forma, existem perspectivas contraditórias dentro do curso. Pelo menos entre o coordenador de curso e os professores.

Ao longo das entrevistas, um ponto discutido também por alguns professores foi com relação à autonomia didática, corroborando com os achados de Rezende e Urbanavicius Júnior (2009). Relatou-se que os professores-titulares ficam relativamente livres para montar suas disciplinas no AVA sem interferência da coordenação ou de diretrizes existentes.

Eu preparo as minhas disciplinas na EAD, o coordenador nunca me deu um feedback do ambiente, se ta bom, se ta ruim. Parece uma ingerência, mas eu me sinto mais autônoma pra fazer o que eu quero.... eu acho que a gente tem mais autonomia talvez pela distância do monitoramento (P6).

Com relação ao mito do profissionalismo, pode-se colocar que não é verificado um dos indicadores (quanto maior a experiência/titulação, maior a confiança recebida). Já com relação ao outro indicador (professores não devem sofrer interferências nas práticas de 


\section{SISTEMAS LEVEMENTE ARTICULADOS E LÓGICA DA CONFIANÇA: O CONTROLE DOS \\ COORDENADORES SOBRE A ATIVIDADE DOCENTE NA EAD ONLINE \\ DOI: http://dx.doi.org/10.5007/1983-4535.2018v11n4p100}

ensino), pode-se notá-lo nos discursos dos entrevistados.

Além do mito do profissionalismo, os professores e outros atores, dentro das organizações educacionais, coadunam de uma forte rejeição a mecanismos de supervisão, principalmente sobre a atividade docente (DANIEL; OKEAFOR, 1987; MEYER; ROWAN, 1978). Esta segunda dimensão da LC procura analisar, então, a postura dos entrevistados frente à existência de mecanismos de supervisão sobre as atividades dos professores.

Ao se analisar as entrevistas, verifica-se certa rejeição a certos tipos de mecanismo de monitoramento, como o feedback dos estudantes do curso. Há docentes que aceitam esse mecanismo informal de monitoramento, mas há outros que discordam fortemente devido ao receio de que a opinião dos alunos possa ser utilizada como único ou o mecanismo preponderante de avaliação.

Então, assim, eu acho que tem que pesar a história do professor como um todo. Às vezes a má interpretação de um aluno prejudica. Então, se o coordenador não conhecer a história... É complicado (P3).

Então, eu penso que é preciso construir outros mecanismos que vão pra além dessa fala do aluno, porque termina que as dificuldades do funcionamento do curso estruturais podem rebater sobre o professor que vão rebater sobre o aluno, mas não é culpa do professor (P10).

Dentro dessa discussão, a própria coordenação reconhece a limitação de depender do respaldo apenas dos alunos. O coordenador de curso e coordenador de tutoria reconhecem a limitação de ser avaliar o desempenho das atividades docentes com base somente na perspectiva dos discentes. Nessa perspectiva, tal preocupação por parte de alguns docentes e da própria coordenação corrobora com os achados de Botelho e Maffra (2009), que expõem a necessidade de que múltiplos mecanismos sejam utilizados para avaliar o desempenho dos professores e não somente a avaliação por parte dos discentes. Todavia, como achado mais importante, e que vai de encontro a essa dimensão da lógica da confiança, aponta-se que os professores não expõem uma postura totalmente contra aos mecanismos de controle, pelo contrário, visto que, na maioria das vezes, o que eles defendem é o seu aperfeiçoamento

Eu acho que todo mundo tem que ser avaliado. Agora, você tem que ter critérios, tem que criar indicadores, esses indicadores têm que ser muito transparente e quem te avalie se possível seja alguém que faça parte daquele processo. Porque, querendo ou não, nós somos corporativistas, então fica difícil você... (P3).

A rejeição a mecanismos de supervisão tem peculiaridades entre os professores 


\section{SISTEMAS LEVEMENTE ARTICULADOS E LÓGICA DA CONFIANÇA: O CONTROLE DOS COORDENADORES SOBRE A ATIVIDADE DOCENTE NA EAD ONLINE \\ DOI: http://dx.doi.org/10.5007/1983-4535.2018v11n4p100}

entrevistados. Embora esses rejeitem o monitoramento constante dos professores-tutores ou mesmo a limitação das atividades e funções desses, não se inclinam contra mecanismos de monitoramento sobre suas atividades por parte da coordenação. Com isso, pode-se ver que contrário aos argumentos de Reponen (1999) e Reis (2009), pelo menos no curso pesquisado, os docentes não se colocam avessos às regras nem ficam reivindicando maior autonomia. Por sua vez, Moore e Kearsley (2011) colocam que a ideia de ser supervisionado não é tão bem compreendida na área acadêmica como é no mundo empresarial. Contudo, acontece que grande parte dos professores entrevistados, e inclusive o coordenador de tutoria, tem vínculo com instituições de ensino superior privadas. Talvez isso torne a utilização de mecanismos de monitoramento mais aceitável e compreensível por parte dos docentes. Aqui também a dimensão ora em análise da lógica da confiança mostra-se enfraquecida. As reclamações frente aos mecanismos de controle aparentam ir de encontro a sua simplificação, mas não contra a existência deles em si. Assim, não se verifica o indicador (rejeição a mecanismos de monitoramento sobre os professores).

A terceira dimensão da LC denomina-se discrição e respeito. Esta aponta que potenciais confrontações com os professores, quando tenham a possibilidade de realmente vir a acontecer, sejam minimizadas (DANIEL; OKEAFOR, 1987). Sendo assim, os coordenadores tendem a mostrar apoio aos professores frente a reclamações para com eles ou alertar previamente os professores sobre supervisões.

Segundo alguns dos entrevistados, há casos nos quais os indivíduos evitam conflitos entre professores ou entre a coordenação e os professores. Por meio da análise das falas dos professores entrevistados, pode-se também notar que a coordenação chama a atenção dos professores de maneira coletiva quando tem que fazer alguma reclamação perante uma postura inadequada dentro do curso.

Em parte, os achados para esta dimensão coadunam com o que defendem Marra e Melo (2005), de que há a tendência dos gestores universitários evitarem conflitos, procurando conversar e negociar, caracterizando, então, uma política de não enfrentamento. Para os autores, a gestão de pessoas nas universidades pode ser tida como uma fonte de desavenças e pressões, pois coordenar pessoas, principalmente quando são seus colegas docentes, os quais podem possuir interesses distintos, e fazer com que eles trabalhem em equipe, é um algo dificultoso.

Com relação à quarta dimensão da LC em (tolerância para com os erros observados), o que se pode notar é que a tolerância existe até que reclamações de alunos, ou 


\section{SISTEMAS LEVEMENTE ARTICULADOS E LÓGICA DA CONFIANÇA: O CONTROLE DOS \\ COORDENADORES SOBRE A ATIVIDADE DOCENTE NA EAD ONLINE \\ DOI: http://dx.doi.org/10.5007/1983-4535.2018v11n4p100}

mesmo outros atores, realmente surjam. Sendo assim, esses aspectos do curso se assemelham aos achados de Hai-Jew (2004), o qual pontua que a coordenação pode apresentar a tendência de só agir e supervisionar os docentes quando há reclamação por parte dos estudantes, em grande parte devido à falta de pessoal para pode proceder com as avaliações de forma constante.

Quando a gente recebe o feedback é só quando o aluno reclama. É no final do semestre, que ta todo mundo querendo dar conta de tudo. Então não é um feedback constante, porque não há um monitoramento constante, assim, é só quando a coisa chega no sinal vermelho (P6).

Nesse sentido, verifica-se que a coordenação possivelmente finge não perceber determinadas posturas. Os coordenadores podem ter conhecimento dessas condutas, contudo, por diversos motivos, a exemplo da incapacidade de monitorar as atividades online dos professores a todo tempo, preferem não verificar mais claramente, pelo menos até surgirem reclamações por parte de alguém para com algum professor. Por outro lado, é difícil verificar o outro indicador da dimensão (tendência de minimizar os erros dos professores), pois professores realmente são punidos e expulsos do curso, embora realmente exista tendência por parte da coordenação em chamar os professores antes de tomar alguma medida.

\section{CONCLUSÃO}

Diante das informações coletadas e analisadas nesta pesquisa, constatou-se que o curso apresenta distintos mecanismos de controle sobre a atividade docente. Por sua vez, o conceito de sistemas levemente articulados mostrou-se condizendo com o lócus investigado. O primeiro elemento, que é a baixa interação e dependência entre os Atores, mostra-se presente, já que na própria EAD a interação entre docentes é bem restrita, inclusive com a coordenação. Com relação à segunda dimensão, problemas permanecem por um longo período sem ser resolvidos dentro do curso. Essa é uma característica bastante presente no caso investigado, principalmente quando se nota que as falas dos coordenadores corroboram com as falas dos entrevistados. Por outro lado, a debilidade dos mecanismos de controle presentes no AVA é nítida. Embora estes mecanismos existam, não são utilizados em toda sua potencialidade, até porque não há pessoas suficientes para refinar os dados. Os atores concordam entre si quando apontam que é grande o número de atores e, por consequência, muitas são as demandas para a coordenação, o que afeta a capacidade desta de monitorar a atividade docente de forma perene. Por fim, o controle cerimonial sobre normas existe quando se nota que as regras muitas vezes são burladas, embora bem delimitadas. Deve-se lembrar que a UAB coloca as 


\section{SISTEMAS LEVEMENTE ARTICULADOS E LÓGICA DA CONFIANÇA: O CONTROLE DOS \\ COORDENADORES SOBRE A ATIVIDADE DOCENTE NA EAD ONLINE \\ DOI: http://dx.doi.org/10.5007/1983-4535.2018v11n4p100}

funções de cada um dentro do curso muito bem especificadas. Todavia, isso não se revela na prática.

O conceito de lógica da confiança mostrou-se mais fraco dentro do curso investigado. De modo geral, podem-se verificar nas falas dos indivíduos, aspectos do conceito, como o mito do profissionalismo e a discrição e respeito. Contudo, elementos como a tolerância para com os erros ou a rejeição a mecanismos de controle mostraram-se mais difíceis de ser aferidos nas falas dos entrevistados, principalmente em relação a uma postura pela rejeição de mecanismos de controle, que não foi encontrada com consistência entre os sujeitos desta pesquisa. Pelo contrário, por vezes podem-se ver questionamentos com relação aos mecanismos de controle no intuito de aperfeiçoá-los.

De forma geral, recomenda-se que mais estudos sejam realizados sobre o processo de controle dentro de cursos de graduação online. Nas futuras pesquisas recomenda-se a utilização de métodos qualitativos à semelhança do que foi feito nesta pesquisa, já que os aspectos do processo de controle costumam apresentar, dentro das organizações, uma lógica informal que, muitas vezes, não é facilmente revelada.

\section{REFERÊNCIAS}

ALMEIDA, A.; PIMENTEL, E. P.; STIUBIENER, I. Estratégias para o monitoramento de ações de tutoria na educação a distância. In: Congresso Brasileiro de Informática na Educação, 2012, Rio de Janeiro. Anais... CBIE: Rio de Janeiro.

ALONSO, K. M. A expansão do ensino superior no Brasil e a EaD: dinâmicas e lugares. Educação e Sociedade, Campinas, v. 31, n. 113, p. 1319-1335, 2010.

AURINI, J. Crafting Legitimation Projects: An institutional analysis of private education businesses. Sociological Forum, v. 21, n. 1, p. 83-111, 2006.

BARDIN, L. Análise de Conteúdo. Lisboa: Edições 70, 2011. 281 p.

BATTISTELLA, L. F.; ARENHARDT, D. L.; GROHMANN, M. Z. A educação a distância e as atribuições do coordenador de curso no Programa Universidade Aberta do Brasil. Revista Electrónica Iberoamericana Sobre Calidad, Eficacia y Cambio en Educación, v. 10, 2012.

BELLONI, M. L. Educação a distância. 5. ed. Campinas: Autores Associados, 2009. 115 p.

BOTELHO, C. S.; MAFFRA, F. R. Didática e competências docentes: um estudo sobre tutoria no curso de administração a distância da Universidade Estadual do Maranhão do Projeto Piloto da UAB. Edapeci, v. 2, n. 2, p. 56-64, 2009.

CAELLI, K.; RAY, L.; MILL, J. “Clear as mud”: toward greater clarity in generic qualitative 
research. International Journal of Qualitative Methods, v. 2, n. 2, p. 1-13, 2003.

CASSUNDÉ, Fernanda Roda de Souza Araújo; MENDONÇA, José Ricardo Costa; BARBOSA, Milka Alves Correia. Influência da estrutura organizacional- administrativa das instituições de ensino superior no desenvolvimento de competências docentes para atuação na EAD. Revista GUAL, Florianópolis, v. 9, n. 2, p. 01-26, maio 2016.

CAVEDON, N. R.; FACHIN, R. C. Homogeneidade versus heterogeneidade cultural: um estudo em uma universidade pública. Organizações \& Sociedade, v. 9, n.25, p. 61-76, 2002.

DANIEL, L. G.; OKEAFOR, K. R. Teaching experience and confidence in teachers. In: Annual Meeting of the Mid-South Educational Research Association. Anais...Mobile: 1987

DEL PINO, M. A. B.; GRUTZMANN, T. P.; PALAU, R. C. N. A educação a distância nas instituições federais de ensino: novas relações no processo de trabalho docente. Cadernos de Educação, v. 38, p. 56-67, 2011.

DENZIN, N. K.; LINCOLN, Y. S. Introdução: a disciplina e a prática da pesquisa qualitativa. In:

DENZIN, N. K.; LINCOLN, Y. S. (Orgs.). O planejamento da pesquisa qualitativa: teorias e abordagens. 2 ed. Porto Alegre: Artmed, 2006.

DIAS JUNIOR, L. D.; FERREIRA, B. Avaliação em ambientes virtuais de aprendizagem: levantamento de requisitos para uma ferramenta de avaliação baseada em participação docente no Moodle e WebCT. Hífen, v. 31, p. 21-29, 2007.

ELIASQUEVICI, M. K.; PRADO JUNIOR, A. C. O papel da incerteza no planejamento de sistemas de educação a distância. Educação e Pesquisa, v. 34, n. 2, p. 309-325, 2008.

HAI-JEW, S. Washington Online virtual campus: infusing culture in dispersed web-based higher education. International Review of Research in Open and Distance Learning, v. 5, n. 2, 2004.

HARDY, C.; FACHIN, R. Gestão estratégica na universidade brasileira: teoria e casos. Porto Alegre: UFRGS, 1996. p.

INEP. Resumo técnico: Censo da educação superior 2014. Brasília: Instituto Nacional de Estudos e Pesquisas Educacionais Anísio Teixeira, 2016.

KICH, J. I. F.; et al. Mudança organizacional: um estudo de caso em tutoria de educação a distância. Revista Eletrônica de Estratégia \& Negócios, v. 5, p. 151-176, 2012.

KONDAKCI, Y; VAN DEN BROECK, H. Institutional imperatives versus emergent dynamics: a case study on continuous change in higher education. Higher Education, v. 58, p. 439-464, 2009.

LAPA, A.; PRETTO, N. L. Educação a distância e precarização do trabalho docente. Em Aberto, Brasília, v. 23, n. 84, p. 79-97, 2010. 
LIMA, L. LOUREIRO, R. C. Controle e poder em ambientes virtuais de aprendizagem. In: Congressso Norte Nordeste de Pesquisa e Inovação, 8., 2012, Palmas. Anais... Palmas: Connepi, 2012.

LINCOLN, Y. S.; GUBA, E. G. Controvérsias paradigmáticas, contradições e confluências emergentes. In: DENZIN, N. K.; LINCOLN, Y. S. (Orgs.). O planejamento da pesquisa qualitativa: teorias e abordagens. 2 ed. Porto Alegre: Artmed, 2006.

LUTZ, F.W. Tightening up loose coupling in organizations of higher education. Administrative Science Quarterly, v. 27, n. 4, p. 653-69, 1982.

MARIZ, L. A. et al. O reinado dos estudos de caso na teoria das organizações: imprecisões e alternativas. Cadernos EBAPE.BR, v. 3, n. 3, p. 1-14, 2005.

MARSHALL, C. Appropriate criteria of trustworthiness and goodness for qualitative research on education organizations. Quality and Quantity, v. 19, p. 353-373, 1985.

MARRA, A.; MELO, M.. A prática social de gerentes universitários em uma instituição pública. Revista de Administração Contemporânea, v. 9, n. 3, p. 9-31, 2005 .

MERCHANT, K. Control Function of Management. Sloan Management Review, v.23, 1982.

MERRIAM, S. Qualitative research and case study applications in education. San Francisco: Jossey-Bass, 1998.

MEYER, J. W. Notes on the structure of educational organizations. In: American Sociological Association Annual Metting. Anais... San Franciso: ASA, 1975.

MEYER, J. W.; ROWAN, B. Institutionalized organizations: formal structure as myth and ceremony. In: DIMAGGIO, P; POWELL, W (Org.). The new institutionalism in organizational analysis, London: University of Chicago Press, p. 41-62, 1991.

MEYER, J. W.; ROWAN, B. The structure of educational organizations. In: ASSOCIATES, MEYER, W. M.; et al. Environments and organizations. San Francisco: Jossey- Bass, 1978.

MINTZBERG, H. Criando organizações eficazes: estruturas em cinco configurações. São Paulo: Atlas, 2011.

MOORE, M. G.; KEARSLEY, G. Educação a distância - uma visão integrada. São Paulo: Cengage Learning, 2011.

MORGAN, G.; SMIRCICH, L. The case for qualitative research. Academy of Management Review, v. 5, n. 4, p. 491-500, 1980.

MORROW, S. Quality and trustworthiness in qualitative research in counseling psychology. Journal of Counseling Psychology, v. 52, n. 2, p. 250-260, 2005. 
OKEAFOR, K. R.; LICATA, J. W.; ECKER, G. Toward a operational definition of the logic of confidence. Journal of Experimental Education, v. 56, n. 1, p. 47-54, 1987.

ORTON, J. D.; WEICK, K. E. Loosely coupled systems: a reconceptualization. Academy of Management Review, v. 15, n. 2, p. 203-223, 1990.

OUCHI, W. G. A conceptual framework for the design of organizational control mechanisms. Management Science, v. 25, n. 9, p. 833-848, 1979.

PÉREZ VILARIÑO, J.; SCHOENHERR, R. Racionalidad y control en las organizaciones complejas. Revista Española de Investigaciones Sociologicas, v. 39, p. 119-39, 1987.

REIS, M. L. Relações entre a prática da educação a distância e a estrutura organizacional das universidades: processos de inovação e a tradição. Eccos. Revista Científica, v. 11, 2009.

REPONEN, T. Is leadership possible at loosely coupled organizations such as universities? Higher Education Policy, v. 12, p. 237-244, 1999.

REZENDE, M. L.; URBANAVICIUS JÚNIOR, V. Caracterização do modelo organizacional de um centro de educação à distância utilizando a teoria de Mintzberg. In: Encontro Internacional do Sistema Universidade Aberta do Brasil, 1., 2009, Brasília. Anais... Brasília: CAPES/UAB, 2009.

VASCONCELOS, I.; PINOCHET, L. A Tecnologia como forma de controle burocrático: uma análise crítica do uso dos sistemas de segurança de informática em uma empresa de alta tecnologia. Revista de Administração Mackenzie, v. 1, n. 1, p. 79-94, 2002.

VASCONCELOS, I.; PINOCHET, L. Poder, tecnologia e controle burocrático: uma análise crozeriana em uma empresa de informática do governo do estado do Paraná. Revista de Administração Pública, v. 38, n. 3, p. 465-479, 2004.

WEICK, K. E. Educational organizations as loosely coupled systems. Administrative Science Quarterly, v. 21, p. 1-19, 1976.

WEICK, K. E. Administering education in loosely coupled schools. Phi Delta Kappan, v. 63, n. 10, p. 673-676, 1982.

ZUIN, A. S. Educação a distância ou educação distante? O Programa Universidade Aberta do Brasil. Educação e Sociedade, n. 96, v. 27, p. 935-934, 2006. 